\title{
Livro traz inventário inédito da produção literária brasileira sobre a ditadura
}

\author{
[ Book brings unpublished inventory of Brazilian literary production on dictatorship
}

\section{Anna Faedrich ${ }^{\mathrm{T}}$}

FIGUEIREDO, Eurídice. A literatura como arquivo da ditadura brasileira. Rio de Janeiro: 7 Letras, 2017 .

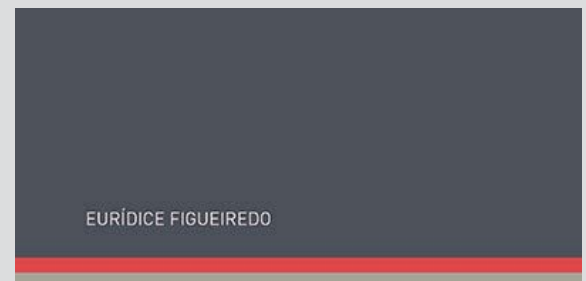

A literatura como arquivo
da ditadura brasileira

Z[เтณง]
A literatura como arquivo da ditadura brasileira, da pesquisadora e professora da Universidade Federal Fluminense Eurídice Figueiredo, revisita o tema da ditadura e da repressão vividas nos anos I968, por um lado, por meio da análise de textos literários que registraram a experiência desse trauma coletivo, funcionando como verdadeiros arquivos, e, por outro lado, revela o testemunho da própria autora sobre o exílio forçado por perseguições. É um livro fundamental no atual cenário literário brasileiro de proliferação de narrativas sobre a ditatura. A combinação entre objetividade e subjetividade, análise crítica da literatura e da realidade, pesquisa acadêmica e relato pessoal, arqueologia literária e memória, dá ao livro um tom peculiar. Dedicada a todos os netos da geração de I968, incluídos os da autora, a obra inicia com epígrafes significativas, que falam sobre o real ficcionalizado, a escrita de um trauma e a história da ditadura militar no Brasil, dialogando com reflexões já realizadas por Jacques Rancière, Maria Rita Kehl, Elio Gaspari e Bernardo Kucinski. Dividida em quatro capítulos, dá o testemunho sobre os tempos difíceis (sobre)vividos na geração I968.

FAEDRICH, Anna. Livro traz inventário inédito da produção literária brasileira sobre a ditadura. S, Brasil, n. 70, p. 292-296, ago. 2018.

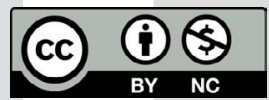

DOI: http://dx.doi.org/Io.II606/issn.23I6-90IX.voi70p292-296

I Universidade do Estado do Rio de Janeiro (UERJ, Rio de Janeiro, RJ, Brasil). 
As questões lançadas pela psicanalista Maria Rita Kehl (20II) - "Quando termina a escrita de um trauma? Quantos anos, ou décadas, são necessários para que um fato traumático se incorpore à memória social sem machucar nem se banalizar? [...] E qual o tempo necessário para se transformar o horror sem sentido em experiência estética compartilhada?" - norteiam a pesquisa de Figueiredo sobre livros que "tematizaram a repressão aos brasileiros que ousaram se rebelar contra a ditadura nos anos I964-I985" (p. I3). O primeiro capítulo, "Os arquivos do mal: memória, esquecimento e perdão", é um panorama histórico do golpe de I964 e dos arquivos da ditadura reunidos em diferentes momentos: no trabalho feito pelo grupo "Brasil: nunca mais”; durante a Comissão Especial sobre Mortos e Desaparecidos; e por ocasião da Comissão Nacional da Verdade3 . Livros recentes também foram decisivos para desvendar os arquivos da ditadura, entre os quais, a trilogia da história da ditadura, do jornalista Elio Gaspari; A casa da vovó (20I4), de Marcelo Godoy; Cova 3 I2 (20I5), de Daniela Arbex; O sargento, o marechal e o faquir (20I6), de Rafael Guimaraens; Lugar nenhum (20I5), de Lucas Figueiredo. A noção derridiana de "arquivo" recebe um espaço especial de análise nesse primeiro capítulo. O conceito de "arquivo do mal”, por exemplo, subsidia a compreensão de todo o livro e por isso dá nome ao

2 O projeto de pesquisa "Brasil: nunca mais" reuniu advogados, religiosos e jornalistas com o objetivo de pesquisar - a partir da análise de 700 processos políticos que transitaram na justiça militar do país - a repressão exercida pelo governo militar no período I964-I979. O projeto "não tem outro objetivo que não seja o de materializar o imperativo escolhido como título da investigação: que nunca mais se repitam as violências, as ignomínias, as injustiças, as perseguições praticadas no Brasil de um passado recente" (BRASIL: nunca mais, I99I, p. 26).

3 A Comissão Nacional da Verdade (CNV) foi composta inicialmente por sete membros - José Carlos Dias, José Paulo Cavalcanti Filho, Maria Rita Kehl, Claudio Lemos Fontelli, Gilson Langaro Dipp, Paulo Sérgio Pinheiro e Rosa Maria Cardoso da Cunha -, nomeados pela então presidente do Brasil Dilma Rousseff, em 2oII, para investigar as violações de direitos humanos no período de I946 a I988. Em 20I3, os conselheiros Gilson Dipp e Claudio Fontelli se desligaram da comissão, e Pedro Bohomoletz de Abreu Dallari foi nomeado. Em 20I4, a CNV entregou o relatório final, concluindo que as práticas de torturas, detenções arbitrárias, violência sexual, execuções, sequestros e ocultação de cadáveres caracterizaram-se como crimes contra a humanidade. Os relatórios estão disponíveis no site http://cnv.memoriasreveladas.gov.br/. 
capítulo: "o arquivo não se confunde com a memória, pelo contrário, ele existe no lugar da memória. $\mathrm{O}$ arquivo é hipomnésico, ele é documento ou monumento, ou seja, os documentos escritos de toda ordem funcionam como elementos de arquivo" (p. 27). Nora, Ricœur, Benjamin, Foucault e Nietzsche se juntam a Derrida para compor a discussão sobre as conexões entre arquivo, memória e esquecimento, perdão. Para Figueiredo, toda obra artística ou histórica, ficções, depoimentos, documentários ou espaços de memória têm valor intrínseco e cumprem também a função de manter viva a memória dos eventos traumáticos e render tributo aos que perseguiram ideais nobres: "[...] Ao rememorar as vítimas, a arte suscita a reflexão, na esperança de que não ocorram novas catástrofes" (p. 35).

Ao final do capítulo inicial, o livro nos devolve ao presente, sob visão crítica e lúcida do "Brasil 20I6" e seus megaeventos não esportivos: as manifestações populares e o impeachment da presidenta Dilma Rousseff. O maior assombro foi perceber o desejo de exumar a ditadura nos chocantes cartazes com votos a favor do regresso militar ao poder político. Figueiredo critica a figura do justiceiro encarnada no judiciário e órgãos de controle, e os riscos da aliança destes com as estratégias da grande imprensa para enaltecer "juízes midiáticos e narcísicos”. A leitura de Eurídice é clara: o afastamento da presidenta Dilma representou um retrocesso social e político, tal qual o golpe há 50 anos. Apoiada nas reflexões do sociólogo Jessé Souza (20I5), a autora compara os dois golpes ocorridos no Brasil, concluindo que não há grandes diferenças entre o golpe de I964 e o "golpismo branco" de 20I6: "[...] prevalece o principal: quem continua mandando é a elite detentora de riquezas, representada na política por uma oligarquia que se perpetua, apoiada por uma classe média manipulada, que despreza os pobres e só olha para o alto da escala social, sem se dar conta de que ela vai "pagar o pato"' (20I7, p. 40).

O segundo capítulo, "A literatura sobre a ditadura: estratégias de escrita", apresenta reflexão sobre o papel da literatura como arquivo da ditadura, considerando a potência do dispositivo literário e da linguagem ordenadora de uma narrativa compreensível. Contra a percepção comum, mesmo entre iniciados, os escritores jovens da nossa literatura abordam os anos de chumbo e recebem tratamento analítico no livro. Adriana Lisboa, Guiomar de Grammont, Tatiana Salem Levy, Luciana Hidalgo, Julián Fuks e Paloma Vidal são postos em evidência pela autora nesse quesito. Figueiredo traz à luz considerável arquivo literário acumulado desde I964, por períodos: (I964 a I979), (I979 a 2000) e (2000 a 20I6). Os "romances emblemáticos" do primeiro período - obras de Frei Betto, Antonio Callado, Carlos Heitor Cony, Ignácio de Loyola Brandão e Renato Tapajós - revelam "os impasses a que levou a luta armada, a tortura e a morte dos militantes, o despreparo das organizações de esquerda que não ofereceram a infraestrutura necessária para realizar a revolução, e, sobretudo, não ofereceram rotas de fuga nem avaliações mais sensatas para se evitar a culpabilização que acarretou tanta morte inutilmente" (p. 63). O período subsequente é marcado ou por relatos autobiográficos ou por romances parcialmente autobiográficos sobre exílio e retorno ao país. Entre os primeiros estão O que é isso, companheiro?, de Fernando Gabeira, Os carbonários, de Alfredo Sirkis, e Primeiro de abril, de Salim Miguel. Tropical sol da liberdade, de Ana Maria Machado, e Amores exilados, de Godofredo de Oliveira Neto, se filiam ao segundo estilo. A autora 
destaca o romance Em liberdade, de Silviano Santiago, denominando-o de "um romance transversal". O destaque recebido é "em termos de elaboração literária" porque Santiago "faz explodir a linearidade e a transparência em benefício de um trabalho formal nos níveis narrativo e estilístico, extrapolando as características mais testemunhais da época” (p. 86). O terceiro período é marcado pelos 50 anos do golpe, que motivou grande número de publicações. Além dos já mencionados Julián Fuks e Paloma Vidal, considerados pela autora como "os filhos do exílio", Guiomar de Grammont e Adriana Lisboa, são tomadas para análise as obras de Marcus Veras, Míriam Leitão, Edney Silvestre, Liniane Haag Brum, Maria Pilla, Maria Valéria Rezende, Beatriz Bracher, Marcelo Rubens Paiva, Edgard Telles Ribeiro e Ivone Benedetti. O capítulo ainda aborda a fortuna crítica e o pioneirismo de Silviano Santiago enquanto crítico literário em escrever sobre a literatura que tematizava a ditadura (“Prosa literária atual no Brasil”, I984).

A subjetividade do livro de Eurídice Figueiredo está presente também na seleção da obra de Bernardo Kucinski, cuja análise compõe um capítulo à parte, o terceiro. A justificativa da predileção tem fundo emocional: "[...] porque foi o autor que mais me impactou e me motivou a prosseguir a pesquisa” (p. 47). “K. de B. Kucinski: Kaddish por uma irmã desaparecida" é o título do capítulo que se inicia pelos fatos da história de desaparecimento da irmã do autor, Ana Rosa Kucinski Silva, e de seu marido Wilson Silva: "O casal foi preso pelo delegado Sérgio Fleury, em 22 de abril de I974, e levado para a Casa da Morte, em Petrópolis, onde foi torturado e executado" (p. I25). Logo após, a autora se dedica à análise da obra de Kucinski, interessada na transfiguração dos fatos em narrativa. Figueiredo distingue $K$. da maioria dos demais por ser escrito no presente, o que confere vitalidade à narrativa; porque o autor se apaga na narrativa e privilegia a figura do velho pai; e pelo estilo enxuto, fragmentário e irônico do autor.

O último capítulo - "Minha terra tem palmeiras... e me expulsaram de lá (Geração I968)" - é o relato pessoal de Eurídice Figueiredo sobre a experiência naqueles anos sombrios da ditadura. A autora se vê obrigada a deixar o país, em I970, após ter a prisão preventiva decretada. Eurídice revela as intempéries que deram tonalidades de aventura à sua "fuga": teve passaporte negado pela Polícia Federal, precisou deixar o Brasil no banco de trás do carro de um contrabandista paraguaio, teve de providenciar passagens para França e passaporte sob o risco de ser presa, sofreu assédio sexual -, felizmente a ajuda de amigos lhe permitiu embarcar rumo à França. Nice foi o local do destino. Embora a França não deixasse de ser uma aspiração para quem era licenciada em Letras-Francês, Eurídice passou momentos angustiantes e de muito abalo emocional durante a adaptação ao país e à nova língua: "Quando tento me lembrar de meus primeiros dias em Nice, vejo que estava desorientada, em todos os sentidos. Depois de um rápido encontro com meus colegas de curso, me despeço sem saber para onde ir: meu senso de direção sendo naturalmente deficiente, o sentimento que tive foi de pânico porque, ao me ver sozinha, não sabia como chegar à residência universitária. Por outro lado, emocionalmente, devia sentir-me abalada, pois estava em outro país, sem poder voltar, exilada e sozinha" (p. I49). As dificuldades pessoais do passado, e agora relembradas, nos aproximam de forma ainda mais íntima do tema do livro. A literatura como arquivo da ditadura brasileira 
é um livro importante por seu registro literário e histórico. Por isso, interessa aos pesquisadores e especialistas em literatura brasileira, aos cientistas sociais e historiadores e, claro, aos que pretendem ampliar o acervo de conhecimento sobre o período. $\mathrm{O}$ estilo de escrita de Figueiredo é claro e objetivo, sem ser simplificador. $\mathrm{O}$ livro, fruto de pesquisa acadêmica sólida, é um inventário inédito de toda a produção literária brasileira sobre a ditadura, e de como os autores brasileiros a retrataram em diferentes períodos. Tornou-se impossível continuarmos afirmando que a literatura brasileira tangencia o tema da ditadura militar. O livro cumpre também um velho e importante papel dos relatos históricos: lançar luz sobre o presente.

\title{
SOBRE A AUTORA
}

\begin{abstract}
ANNA FAEDRICH é professora adjunta do Colégio de Aplicação da Universidade do Estado do Rio de Janeiro (CAp-UERJ), professora colaboradora do Programa de Pós-Graduação Lato Sensu em Literatura Brasileira da Universidade do Estado do Rio de Janeiro (UERJ) e tutora da disciplina Literatura Comparada da Universidade Federal Fluminense (UFF) E-mail: anna.faedrich@gmail.com
\end{abstract}

\section{REFERÊNCIAS}

BRASIL: nunca mais. Prefácio de Dom Paulo Evaristo Arns. São Paulo: Vozes, I99I.

CNV - Comissão Nacional da Verdade. A Comissão Nacional da Verdade (CNV), órgão temporário criado pela Lei I2.528, de I8 de novembro de 20II, encerrou suas atividades em Io de dezembro de 20I4, com a entrega de seu Relatório Final. Esta cópia do portal da CNV é mantida pelo Centro de Referência Memórias Reveladas, do Arquivo Nacional. Disponível em: 〈http://cnv.memoriasreveladas.gov.br〉. Acesso em: jun. 2018.

DERRIDA, Jacques. Mal de arquivo: uma impressão freudiana. Tradução Cláudia de Moraes Rego. Rio de Janeiro: Relume Dumará, 200I.

KUCINSKI, Bernardo. K: relato de uma busca. São Paulo: Cosac Naify, 2014.

RANCIÈRE, Jacques. A partilha do sensível: estética e política. Tradução de Mônica Costa Netto. São Paulo: Editora 34, 2009.

Se o irrepresentável existe. In: . O destino das imagens. Tradução de Mônica Costa Netto. Rio

de Janeiro: Contraponto, 20I2, p. II9-I49.

SANTIAGO, Silviano. Em liberdade. Rio de Janeiro: Rocco, I98I.

SOUZA, Jessé. A tolice da inteligência brasileira: ou como o país se deixa manipular pela elite. São Paulo: Leya, 2015 . 